\title{
Research on the Current Situation and Countermeasures of Crisis Management in Higher Vocational Colleges based on the Network

\author{
Zhao Nan
}

School of Economics and Management, Tianjin University of Technology and Education NO.1306,dagu south Road, Hexi District, Tianjin city

15222247795@163.com

Key words: Higher Vocational Colleges; Crisis Management; Cooperative Governance; Network

\begin{abstract}
The campus crisis based on the network media has a new change which is different from the traditional campus crisis. Its spreading speed and wide range challenge ability of the school managers to deal with the crisis. The research on the school crisis management in China has the phenomenon of "hot and cold alternation", which lacks the systematic management system. On the basis of summarizing the characteristics of crisis events and the current situation of crisis management based on the network, this thesis applies the basic three-part model of crisis management, and emphasizes the participation of schools, governments, online media and social organizations.
\end{abstract}

\section{网络背景下高职院校危机管理现状及对策研究}

\author{
赵楠 \\ 天津职业技术师范大学经济与管理学院 河西 天津 中国 \\ 天津河西区大沽南路1306号 \\ 15222247795@163.com
}

关键词：高职院校；危机管理；合作治理；网络

摘要. 网络媒体下的校园危机事件有了不同于传统校园危机的新变化, 其传播速度快、范围广 的特点对学校管理者应对危机事件的能力提出了挑战。我国关于学校危机管理的研究存在“冷 热交替” 现象, 缺少系统的管理体系。本文在总结网络背景下高职院校危机事件特点、危机 管理现状的基础上, 从危机管理中基本的三分模型入手, 强调学校、政府、网络媒体和社会 组织的共同参与。

\section{1. 引言}

学校是社会环境中的一个子系统，在其发展过程中不可避免地会受到社会大环境的影响。 职业院校人口密集、生源背景复杂，且管理方法不同于普通院校，这些因素的存在使职业院 校更容易成为危机事件的高发地。网络在危机事件中是一把双刃剑, 一方面拓宽了人们获取 信息的渠道, 提高了信息传播速度, 另一方面其信息传播高速性也对学校处理危机问题的能 力提出更高要求。因此, 高职院校要与时俱进地了解网络时代危机事件的特点, 利用网络媒 介的积极方面，整合各方资源建立起有效应对危机事件的反应机制。 


\section{2. 网络影响下的职业院校危机事件}

\section{1 职业院校危机事件概述}

美国学者罗森豪尔特认为危机是对一个社会系统的基本价值和行为准则架构形成严重威 胁, 并且在时间压力和不确定性极高的情况下必须对其做出关键决策的事件 ${ }^{[1]}$ 。危机事件具 有意外性、破坏性、紧迫性和聚焦性的特点。高职院校危机事件是一般危机事件在学校情景 下的具体表现，具有危机事件的共性特点，而高职院校学生认知发展水平、年龄分布特点以 及学校管理制度等多方面因素也导致了高职学校危机事件具有一定的个性特点。

学校危机事件多产生于学生间的意外事件。从认知层面来说, 职业院校学生发展水平要 低于普通院校学生, 这也意味着职业院校学生更易发生意外事件。从心理层面来说, 高职院 校学生多处于青少年期, 该年龄段学生易冲动, 受外界影响比较大, 因此小规模意外事件处 理不当，很容易造成大范围危机事件，这体现了高职院校危机事件发生的结构不良性 ${ }^{[2]}$ 。

\section{2 网络对危机事件的影响}

网络技术的高速发展为人们的生活带来了极大的便利, 各种网站、社交软件的使用丰富 了信息传播的传统媒介。网络影响下的危机事件也展现了不同于早前危机事件的新特点。网 络媒体的一个重要特点就是信息传播的极速化。青少年是目前最为活跃的网民群体，他们极 有可能将学校发生的危机事件诉诸网络, 使之上升为全民话题, 加大事件的不可控性, 最后 成为影响院校形象的危机事件。网络技术可以跨越地区障碍, 实现不同地域间的信息交流。 在网络的影响下，危机事件的影响会像 “蝴蝶效应”一般持续夢延。危机事件造成的负面影 响将不再局限于事发学校。网络媒体背景下, 高职院校危机事件的诱因也逐渐增加, 即学校 危机事件的致灾因子多元化 ${ }^{[3]}$ 。

\section{3. 网络影响下职业院校危机管理}

对于危机管理进行系统研究起始于上世纪九十年代初, 我国学者张成福对危机管理做了 如下定义: 危机管理是一种有组织、有计划、持续动态的管理过程, 政府针对潜在的或者当 前的危机，在危机发展的不同阶段采取一系列的控制措施，以期有效的预防、处理和消揖危 机 ${ }^{[4]}$ 。由此可知, 危机管理是一个动态的过程, 涉及危机发生之前的预防和监管、危机发生 之时的及时应对和处理、危机发生之后的恢复和学习, 这是危机管理最基本的三阶段模型。

\section{1 职业院校危机管理}

高职院校危机管理，顾名思义，就是学校管理者对可能引发危机事件的因素进行实时监 控和预防, 对已经发生的危机事件采取积极的应对措施来减小损失, 降低负面影响, 对已经 解决的危机事件做好善后事宜, 汲取教训的过程。高职院校危机管理应是一个循环往复的过 程, 解决危机事件、汲取相关教训是为了提高学校服务质量, 保证学校秩序正常进行, 建设 更好的校园环境，进而减小危机事件发生的概率，做好危机事件的预防工作。

\section{2 网络媒介对学校危机管理的影响}

网络是把双刃剑，对危机管理有利有弊。一方面，危机管理具有时效性，学校管理者要 在短时间内快速做出反应, 防止事件影响扩大。网络媒体的快速发展无疑在不断 “压缩” 学 校管理者应对危机的反应时间; 同时网络社交平台的匿名制也为谣言的滋生提供了便利条件, 很多不实信息的传播增加学校危机管理的难度, 造成危机事件的愈演愈烈。另一方面, 发达 的网络系统方便管理者实时了解危机事件的影响, 通过了解社会舆论, 集中民智的方法来调 整危机事件的处理策略; 学校管理者也可以通过网络平台发布危机事件的处理进度, 实现学 校内外的信息交换，引导正确的舆论走向。 


\section{3 学校使用网络媒介处理危机的现状}

正确地使用网络技术, 学校处理危机事件的效果将事半功倍。就现状而言, 很多学校利 用网络技术处理危机事件的经验贵乏, 致使学校在危机事件中常常处于被动境地。一方面, 学校缺少相关技术部门。危机事件发生时学校要在第一时间做出反应, 做好信息发布、解疑 答问的工作，避免不实信息借助网络快速传播，扩大负面影响。在实际工作中，高职院校普 遍存在重教学、轻管理、相关技术人员缺位，网络信息发布机制不健全的问题。学校一般在 危机事件不可控时才会采取补救措施, 例如北京中关二小案例, 这显然不符合危机管理时效 性的特点。另一方面, 学校缺少对学生的正确引导。青少年期的学生虽有一定的是非观, 但 缺乏对网络信息甄别的能力, 容易被虚假信息所误导, 这是学校危机事件发生的潜在因素, 不加以干预就不利于学校对危机事件的预防和控制。

\section{4. 基于网络的校园危机事件协同治理}

危机既是危险也是机遇, 选择合适方式处理危机有助于提升学校形象、增强学生的危机 意识, 避免相似危机事件的再次发生 ${ }^{[3]}$ 。网络影响下的危机事件已经跨越学校围墙, 成为影 响社会的热点问题。因此, 在网络技术高速发展的今天, 对高职院校危机事件进行处理既发 挥学校的主体作用, 又要通过互联网将利益相关者连接起来, 发挥各组织的积极作用, 实现 全面整合的危机管理模式。危机事件管理过程可以简单分为预防、处理和恢复三个阶段, 三 阶段环环相扣、密不可分。解决危机事件, 减小危机事件带来的影响, 各组织机构也需要从 这三个阶段入手。

\section{1 危机之前的预防控制阶段}

发挥学校在校园危机管理过程中的主体作用和政府的监督作用。学校的责任不仅是对学 生进行文化知识教育, 还要对学生进行思想层面的教育, 从理论上培养学生预防、应对各种 危机事件的意识, 将学生危机意识的培养情况纳入学校的测评系统。进行改革只靠学校主体 的意愿在实行方面会有困难, 政府可以通过政策法规的制定将其制度化, 减小学校在实施层 面上的阻力。学校应建立系统完善的危机预警机制, 对诸如食品安全、设施安全和校园暴力 等学校内部的潜在致灾因子进行监管, 如有问题及时向上级政府反映, 获取技术支持, 避免 由量向质的快速转变。

校园危机事件的发生既有个性又有共性。同一地区不同院校之间应该建立共同预防危机 事件的合作机制, 通过建立危机事件的网络数据库实现资源共享, 以此预防校园危机事件的 发生。对于学校管理者来说, 通过了解其他院校已经发生的危机事件和处理方法, 可以有效 地对学校内可能存在的同类致灾因子进行管理，真正做到防患于未然。

学校缺少相关的危机管理机构, 也没有针对突发事件而进行的危机应对技能的培训, 这 一现状不仅需要政府进行监督健全学校危机治理职能, 也需要社会公益组织的介入, 对学校 相关管理部门进行技能培训, 为学校处理危机事件提供外援帮助。只有当学校做好了应对危 机事件的准备工作，才能在危机事件发生时采取冷静、快速、有效的对应措施。

\section{2 危机发生时的处理阶段}

对学校来说要基于危机反应力建立网络媒体预警机制[5]。危机事件发生时学校要平衡好 学校内部和外部的关系, 对内要有条不紊地处理问题, 稳定师生情绪, 保证教学秩序的正常 进行, 对外要通过网络媒体例如微博、网上直播等, 如实发布处理信息, 积极回应外界媒体 和群众质疑, 引导正确的與论导向, 防止由于不回应或者模糊回应而产生谣言, 造成对学校 形象和师生群体的二次伤害。网络媒体有着较强的互动性, 网络媒体一方面要反应群众的要 求, 将群众的相关疑问反映给学校管理者, 另一方面, 网络媒体又要做到监督学校处理危机 事件的进展情况, 开通专门通道对危机事件随时跟进, 保证信息的公开透明, 避免民众猜忌 
和恐慌。最后网络媒体对危机事件进行报道, 要做到公正负责, 不用偏激言论或失真报道进 行炒作，引导群众以理性态度来对待危机事件。

\section{3 危机事件后的恢复阶段}

危机事件解决后，学校要采取善后措施来消除危机事件带来的负面影响，这种善后措施 既包括危机事件中被破坏的校园设施、学校秩序进行恢复，也包括对危机事件中受影响的师 生全体进行心理恢复，这一阶段同样需要学校和政府、社会公益组织共同努力来完成。

政府作为公共服务者，要对危机事件后学校的各项建设提供帮扶政策。财政支持可以有 效解决学校基础设施建设经费不足的问题; 政府的强制手段可以为校园提供一个良好的外部 环境, 减少危机事件的外部诱因; 同时, 要积极动员社会力量帮助学校度过难关; 危机事件 产生反映了学校管理上存在的漏洞, 政府要担负起监管的责任。建立健全政策法规和追责制 度可以有效解决学校处理危机事件时无法可依的现象。

社会组织要积极担负起对危机事件中受影响的师生要进行危机干预的工作重任。学校危 机事件的影响往往是巨大的, 受波及师生较多, 通过校外组织的介入, 可以减轻学校恢复阶 段的压力, 使恢复阶段的各项工作更有成效。在校外公益组织和学校的合作中, 社会组织可 充分发挥自身优势，对学校师生进行心理疏导。

管理方面, 学校要汲取教训、对危机事件的产生进行反思回顾, 同时要配合政府工作完 善学校在管理中存在的漏洞, 接受政府和社会成员的监管和监督, 努力杜绝相似事件的再发 生。服务方面, 学校要提高自身服务学生的水平, 对全校师生进行安抚工作, 积极组织进行 心理健康教育, 把危机后的附加影响降到最低, 争取校园良好形象的重塑。

\section{5. 总结}

网络媒体下高职院校危机呈现的新特点, 要求我们在危机管理时综合利用资源, 发挥各 组织部门的能动性，建立危机治理协同机制，进而最大限度地减小危机事件的影响。

\section{致谢}

本文为天津职业技术师范大学科研发展基金资助项目 项目编号SK13-12。

\section{References}

[1] Rosenthal Uriel \& Charles Michael T., Co Ping with Crisis:The Management of Disarsters, Riots and Terrorism, Springfield: Charles C. Thomas, 1989.7-8.

[2] Sun Liang. Research on the application of network media in the process of crisis management in Colleges and universities [D]. Shanghai: School of international and public affairs, Shanghai Jiao Tong University, 2010

[3] Liao Jinping, Song Qingmei. Study on crisis coordination management in Higher Vocational Colleges under the background of new media [J]. Vocational Education Forum.2016,13

[4] Zhang Chengfu. Public crisis management: a fully integrated model and strategic choice of China [J]. China Administration, 2003,7: 6

[5] Wang Yangyang, Li Shufeng. School crisis management: an analysis based on the Internet media $[\mathrm{J}]$. contemporary education science.2013,4 